\title{
Mechanism of Peripheral Noradrenergic Stimulation by Clozapine
}

\author{
Igor Elman, M.D., David S. Goldstein, M.D., Ph.D., Graeme Eisenhofer, Ph.D., Joan Folio, R.N.,
} Anil K. Malhotra, M.D., Caleb M. Adler, M.D., David Pickar, M.D., and Alan Breier, M.D.

Elevated plasma norepinephrine (NE) levels is a relatively consistent clinical effect of clozapine. Plasma NE levels reflect an interplay of release, reuptake, metabolism, and excretion. To explore the mechanism of clozapine-induced plasma NE elevation, we measured arterial plasma levels of $N E$ and other catechols during intravenous infusion of tritium-labeled NE $\left({ }^{3} \mathrm{H}-\mathrm{NE}\right)$ in schizophrenic patients treated with clozapine, fluphenazine, or placebo. Clozapinetreated patients had markedly higher levels of NE than did the patients treated with fluphenazine or placebo. NE spillover averaged more than three times higher in clozapine-treated patients; whereas NE clearance did not differ among the groups. Production of

KEY WORDS: Schizophrenia; Norepinephrine; Clozapine; Catecholamine; Fluphenazine; Spillover

Clozapine is an atypical neuroleptic with efficacy superior to that of conventional antipsychotic agents (Kane et al. 1988; Leiberman et al. 1989; Breier et al. 1994a; Breier et al. 1994b; Meltzer 1995; Meltzer et al. 1996). A relatively consistent clinical effect of clozapine is a robust increase in norepinephrine (NE) levels, both in cerebrospinal fluid (CSF) (Ackenheil 1989; Leiberman et al. 1989; Leiberman et al. 1991; Pickar et al. 1992) and in plasma (Pickar et al. 1992; Green et al. 1993; Davidson et al. 1993; Breier et al. 1994b; Breier 1994; Brown et al.

From the Experimental Therapeutics Branch (IE, AKM, CMA, DP, AB), Clinical Neuroscience Branch (DSG, GE, JF), National Institute of Mental Health, National Institutes of Health, Bethesda, Maryland.

Address correspondence to: Igor Elman, M.D., Massachusetts General Hospital, Harvard Medical School, West End House, 16 Blossom Street, Boston, Massachusetts 02114, USA.

Received 6 November 1997; revised 1 April 1998; accepted 15 April 1998.
${ }^{3} \mathrm{H}$-dihydroxyphenylglycol $\left({ }^{3} \mathrm{H}-\mathrm{DHPG}\right)$, a purely intraneuronal metabolite of ${ }^{3} \mathrm{H}-\mathrm{NE}$ in clozapine-treated patients was normal, indicating that clozapine did not affect neuronal uptake of NE. Because plasma levels of DHPG and dihydroxyphenylacetic acid (DOPAC), deaminated metabolites of catecholamines, in clozapine-treated patients were normal, clozapine also did not seem to inhibit intraneuronal monoamine oxidase (MAO). High plasma NE levels in clozapine-treated patients, therefore, resulted from increased NE spillover rather than decreased reuptake, metabolism, or clearance.

[Neuropsychopharmacology 20:29-34, 1999]

Published by Elsevier Science Inc.

1997). Plasma NE increases have been related to clinical improvement (Breier et al. 1994b; Breier 1994), suggesting that this neurochemical effect may be involved in clozapine's therapeutic mechanism of action. In contrast, traditional antipsychotic agents studied to date have no or negligible influence on NE levels (Pickar et al. 1992; Breier et al. 1994b; Brown et al. 1997).

The mechanism of clozapine-induced NE elevation has not been established. Plasma levels of any endogenous biochemical represent the ratio of the rate of release of the substance into the bloodstream (spillover) and clearance of the substance from the bloodstream. Clozapine-induced elevations in plasma NE levels, therefore, could result from increased spillover, deceased clearance, or a combination of both.

Neuronal uptake by sympathetic nerves constitutes a determinant of plasma NE spillover (Eisenhofer et al. 1996) and clearance (Esler et al. 1981; Eisenhofer et al. 1991). After neuronal uptake of NE, some of the NE in the axoplasm undergoes oxidative deamination by mitochondrial monoamine oxidase (MAO), forming dihy- 
droxyphenylglycol (DHPG). Inhibition of neuronal uptake, therefore, could explain the finding of normal plasma DHPG levels, despite high plasma NE levels, in clozapine-treated patients (Breier et al. 1994b; Breier 1994).

The present study applied a comprehensive neurochemical approach to examine the mechanisms responsible for clozapine-induced elevations in plasma NE concentrations. This approach was based on intravenous infusion of tracer amounts of ${ }^{3} \mathrm{H}-\mathrm{NE}$ in schizophrenic patients treated with clozapine, fluphenazine, or placebo. Because formation of ${ }^{3} \mathrm{H}$-DHPG from ${ }^{3} \mathrm{H}-\mathrm{NE}$ requires both neuronal uptake and intraneuronal deamination by $\mathrm{MAO}$, measurement of plasma ${ }^{3} \mathrm{H}-\mathrm{DHPG}$ responses provided the basis for assessing both of these processes. Plasma levels of the NE precursor dihydroxyphenylalanine (DOPA) and of the dopamine metabolite DOPAC were also examined to provide information about NE synthesis and further information about intraneuronal metabolism by MAO.

\section{METHODS}

\section{Subjects}

Ten clozapine-, 7 fluphenazine-, and 7 placebo-treated patients meeting DSM-IV criteria for schizophrenia, as determined by structured diagnostic interview, underwent this study at the National Institutes of Health Clinical Center. All subjects gave written informed consent to participate in the protocol, which was approved by the National Institute of Mental Health Review Board. All subjects were in good physical health, as evidenced by physical examination, ECG, and screening blood tests. The treatment groups did not differ in demographic or clinical characteristics (Table 1).

The patients were on a stable dose of medication or medications free for a minimum of 2 weeks. Doses were varied to achieve maximal clinical efficacy (clozapine mean dose \pm SD: $385.00 \pm 178.4 \mathrm{mg}$ per day; fluphenazine mean dose \pm SD: $21.02 \pm 3.95 \mathrm{mg}$ per day).

\section{Procedure}

The subjects were studied after having fasted and refrained from alcohol, tobacco, caffeine, or physical activity for at least 10 hours. With the patient supine, an arterial catheter was inserted percutaneously in a radial artery after local anesthesia of the overlying skin. An antecubital intravenous catheter was inserted into the contralateral arm. After $60 \mathrm{~min},{ }^{3} \mathrm{H}-\mathrm{NE}\left(\left[1,7-{ }^{3} \mathrm{H}\right] \mathrm{NE}\right.$, 14$22 \mathrm{Ci} / \mathrm{mmol}$; New England Nuclear, Boston, MA) in 50 cc normal saline was infused intravenously at $0.75 \mathrm{ml} /$ min. Arterial blood samples $(7-8 \mathrm{ml})$ were obtained at $15,30,45$, and $60 \mathrm{~min}$ after the ${ }^{3} \mathrm{H}-\mathrm{NE}$ infusion began.

\section{Biochemical Variables}

Blood for assays was collected in heparinized tubes and placed on wet ice. After separation by refrigerated centrifugation, the plasma was stored at $-80^{\circ} \mathrm{C}$. Plasma catechol levels were assayed using liquid chromatography with electrochemical detection (Eisenhofer et al. 1986). Concentrations of ${ }^{3} \mathrm{H}-\mathrm{NE}$ and ${ }^{3} \mathrm{H}-\mathrm{DHPG}$ were measured by scintillation spectrometry on effluent from the chromatographic column (Eisenhofer et al. 1991). Interassay coefficients of variation were $6.5 \%$ for $\mathrm{NE}$, $3.9 \%$ for ${ }^{3} \mathrm{H}-\mathrm{NE}, 8.4 \%$ for DHPG, $4.7 \%$ for ${ }^{3} \mathrm{H}-\mathrm{DHPG}$, $5.9 \%$ for DOPA, and $11.6 \%$ for DOPAC. Intra-assay coefficients of variations were $1.9 \%$ for NE, $3.2 \%$ for ${ }^{3} \mathrm{H}-$ $\mathrm{NE}, 3.7 \%$ for DHPG, $7.6 \%$ for ${ }^{3} \mathrm{H}-\mathrm{DHPG}, 3.8 \%$ for DOPA, and $3.9 \%$ for DOPAC.

The rate of release of endogenous NE into arterial plasma and the rate of clearance from plasma was determined with the following equations: $C L=I R /\left[{ }^{3} \mathrm{H}\right]-$ $\mathrm{NE}$; $S P=C L \times \mathrm{NE}_{a}$, where $C L$ is the arterial plasma NE clearance $(\mathrm{ml} / \mathrm{min}), I R$ is the infusion rate of $\left[{ }^{3} \mathrm{H}\right]-\mathrm{NE}$, $\left[{ }^{3} \mathrm{H}\right]-\mathrm{NE}$ is the arterial plasma concentration of $\left[{ }^{3} \mathrm{H}\right]-\mathrm{NE}$, $S P$ is the NE spillover rate $(\mathrm{pmol} / \mathrm{min})$ into arterial plasma, and $\mathrm{NE}_{a}$ is the arterial plasma concentration of endogenous NE (Esler et al. 1979). Neuronal uptake (Eisenhofer et al. 1991) and NE stores (Eisenhofer et al. 1991; Eisenhofer et al. 1996) were assessed from the ${ }^{3} \mathrm{H}$ DHPG and ${ }^{3} \mathrm{H}-\mathrm{NE}$ concentrations.

Table 1. Demographic and Clinical Characteristics ${ }^{a}$ of Schizophrenic Patients Treated with Clozapine $(n=10)$, Fluphenazine $(n=7)$, and Placebo $(n=7)$

\begin{tabular}{lcccc}
\hline Patient Characteristic & Clozapine & Fluphenazine & Placebo & F, $d f, \boldsymbol{p}$ \\
\hline Age $(\mathrm{yr})$ & $38.0(8.7)$ & $39.3(7.7)$ & $43.6(4.4)$ & $1.21,2,0.32$ \\
Sex $^{b}(\mathrm{M} / \mathrm{F})$ & $9 / 1$ & $4 / 3$ & $5 / 2$ & \\
Age of onset (yr) & $20.1(6.8)$ & $26.9(6.5)$ & $27.1(8.4)$ & $2.7,2,0.09$ \\
Duration of illness (yr) & $17.9(12.9)$ & $12.4(6.1)$ & $16.4(9.1)$ & $0.60,2,0.56$ \\
No. hospitalizations & $9.5(8.1)$ & $9.3(10.4)$ & $4.4(4.2)$ & $0.97,2,0.40$
\end{tabular}

${ }^{a}$ Data are presented as mean (standard deviation).

${ }^{b} \chi^{2}=2.44, d f=2, p=.30$. 


\section{Statistical Analyses}

The data were analyzed using Statistica (StatSoft, Inc., Tulsa OK 74104). Results across the 4 sampling points were averaged and expressed as means \pm standard deviation (SD). Differences among the treatment groups were assessed by one-way repeated-measures analysis of variance (ANOVAs), with drug condition (clozapine, fluphenazine, placebo) as the grouping factor. When a group effect was significant, post hoc Newman-Keuls $t$-tests were performed. Time-related trends in ${ }^{3} \mathrm{H}-\mathrm{DHPG} /$ ${ }^{3} \mathrm{H}-\mathrm{NE}$ ratios were examined by two-way ANOVAs, with drug condition as the grouping factor and time as the within-subjects factor. A $p$ value less than .05 defined statistical significance. All tests were two-tailed.

\section{RESULTS}

\section{Catechol Levels}

Clozapine-treated patients had more than three times higher arterial plasma NE levels $(\mathrm{F}=9.39 ; \mathrm{df}=2 ; p=$ .001 , Figure 1) than patients treated with fluphenazine or placebo. Post hoc analyses revealed significantly higher NE levels in subjects treated with clozapine than with fluphenazine $(p=.002)$ or placebo $(p=.005)$. There were no significant NE differences between fluphenazine and placebo treatment groups. The groups did not differ in plasma levels of DOPA or DOPAC (Table 2).

\section{NE Spillover}

NE spillover was increased by more than threefold in clozapine-treated patients $(\mathrm{F}=9.41 ; \mathrm{df}=2 ; p=.001)$ (Figure 1), as compared with both of the other groups (fluphenazine, $p=.004$; placebo, $p=.002$ ). Fluphenazine did not alter NE spillover.

\section{NE Clearance}

The three treatment groups did not differ in plasma NE clearance $(\mathrm{F}=0.42 ; \mathrm{df}=2 ; p=.66)$ (Figure 1$)$.

\section{Time-Related Trends in ${ }^{3} \mathrm{H}-\mathrm{DHPG} /{ }^{3} \mathrm{H}-\mathrm{NE}$ Ratio}

${ }^{3} \mathrm{H}-\mathrm{DHPG} /{ }^{3} \mathrm{H}-\mathrm{NE}$ ratios increased progressively with time $(\mathrm{F}=18.53 ; \mathrm{df}=3 ; p<.0001)$. The increases did not differ among the groups, as indicated by a statistically nonsignificant interaction effect for group with time $(\mathrm{F}=0.91 ; \mathrm{df}=6,3 ; p=.49$, Figure 2$)$.

\section{DISCUSSION}

The major finding of this study is that high plasma NE levels in clozapine-treated patients result entirely from
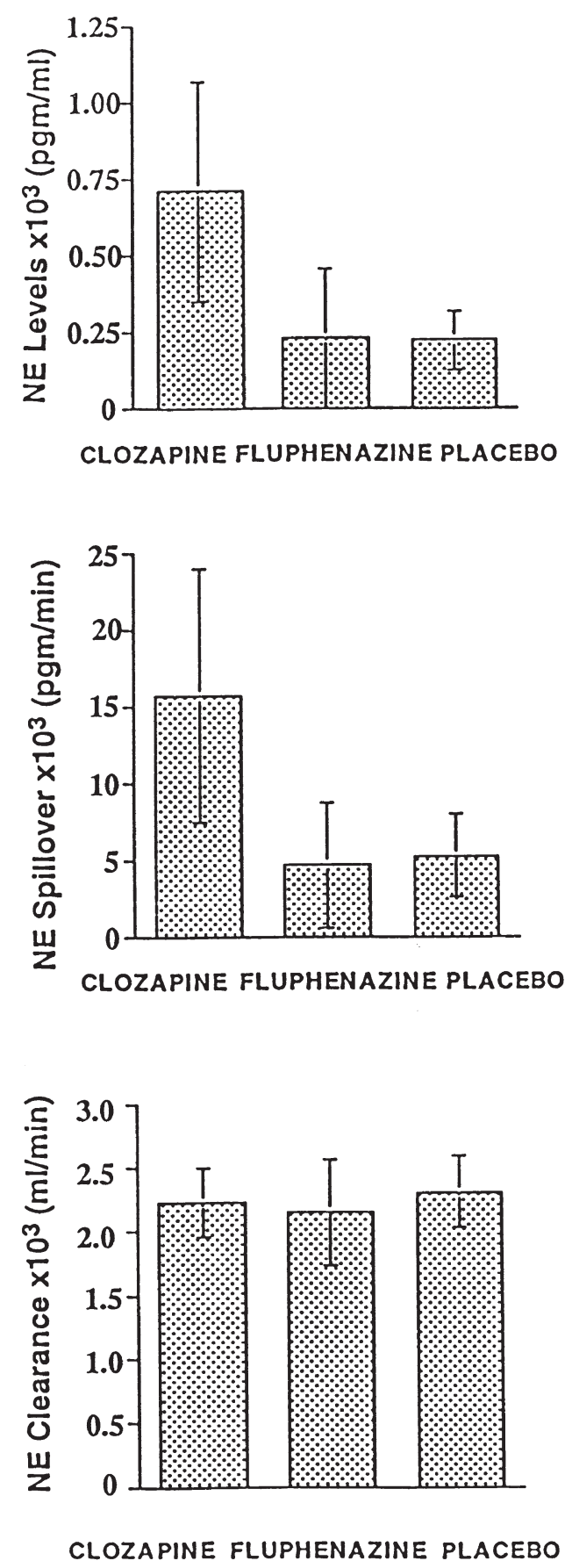

Figure 1. NE plasma level, NE spillover, and NE clearance in schizophrenic patients treated with clozapine $(n=10)$, fluphenazine $(n=7)$, and placebo $(n=7)$.

increased NE spillover and not from decreased clearance. Several factors determine NE spillover, other than exocytotic release in response to sympathetic nerve traffic. Probably the most important is reuptake. Estimates of the efficiency of reuptake of endogenously released NE range up to about 90\% (Iversen 1973; Esler et al. 1990). Clearly, even a small amount of inhibition of re- 
Table 2. Arterial Plasma Catechol Levels ${ }^{a}(\mathrm{pgm} / \mathrm{ml})$ in Schizophrenic Patients Treated with Clozapine $(n=10)$, Fluphenazine $(n=7)$, and Placebo $(n=7)$

\begin{tabular}{lrrrr}
\hline Catechol & Clozapine & Fluphenazine & Placebo & F, $\boldsymbol{d} f, \boldsymbol{p}$ \\
\hline DHPG & $721.78(137.99)$ & $831.36(361.31)$ & $765.25(177.48)$ & $0.45,2,0.64$ \\
DOPA & $1490.75(271.54)$ & $1394.21(213.84)$ & $1362.18(271.54)$ & $0.56,2,0.58$ \\
DOPAC & $1303.86(196.23)$ & $1290.57(447.94)$ & $1043.08(551.37)$ & $1.17,2,0.33$ \\
\hline
\end{tabular}

${ }^{a}$ Data are presented as mean (standard deviation).

uptake would augment the amount of NE entering the plasma for a given rate of exocytotic release from the terminals. The finding of high plasma NE levels without a corresponding increase in plasma DHPG would support this sort of mechanism, because plasma DHPG reflects the metabolism of axoplasmic NE (Goldstein et al. 1988; Goldstein 1995). All other things being the same, decreased reuptake of NE would increase NE spillover but decrease plasma DHPG levels. Because we previously observed this pattern in clozapine-treated patients (Breier et al. 1994b), the present study focused especially on the issue of possible neuronal uptake blockade by clozapine.

Neuronal reuptake contributes to clearance of circulating NE in humans (Esler et al. 1981; Eisenhofer et al. 1991). The present finding of no change in NE clearance in clozapine-treated patients argues against inhibition of neuronal uptake as a basis for high plasma NE levels in these patients. To examine neuronal uptake more specifically, we measured the arterial plasma ${ }^{3} \mathrm{H}-\mathrm{DHPG}$

Time Effect $(\mathrm{F}=18.53 ; \mathrm{df}=3 ; \mathrm{p}<0.00001)$

Group effect-N.S.

Group x Time-N.S.

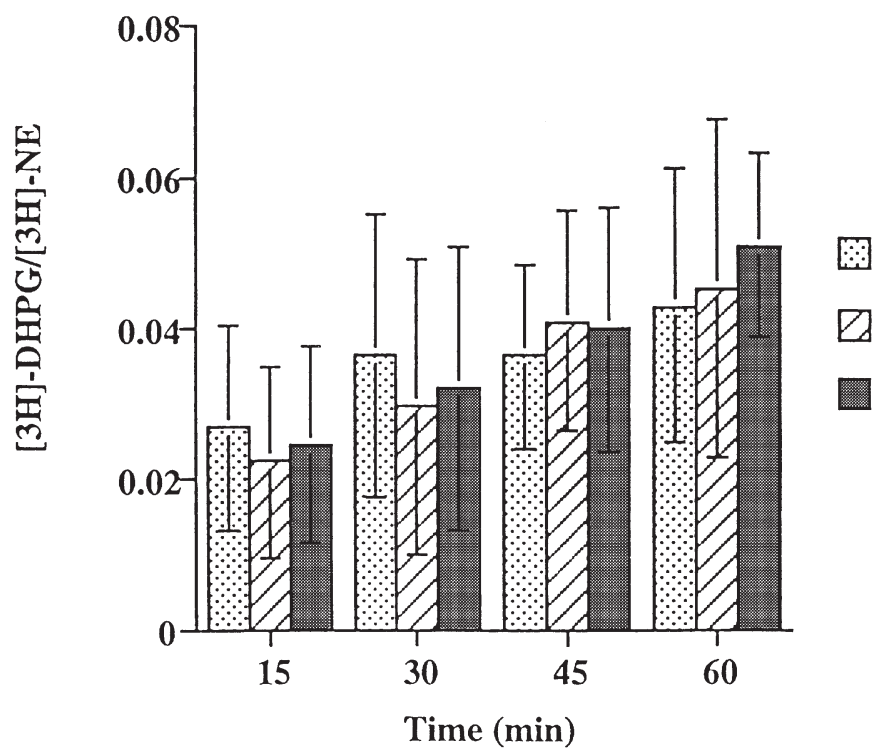

response during ${ }^{3} \mathrm{H}-\mathrm{NE}$ infusion. Production of ${ }^{3} \mathrm{H}-$ DHPG did not differ among the treatment groups, with or without correction of ${ }^{3} \mathrm{H}-\mathrm{DHPG}$ levels for concurrent plasma ${ }^{3} \mathrm{H}-\mathrm{NE}$ levels. Because ${ }^{3} \mathrm{H}-\mathrm{DHPG}$ production in this setting results virtually exclusively from metabolism of ${ }^{3} \mathrm{H}-\mathrm{NE}$ in the sympathetic axoplasm (Goldstein et al. 1988; Goldstein 1995), the finding of normal ${ }^{3} \mathrm{H}$ DHPG and ${ }^{3} \mathrm{H}-\mathrm{DHPG}:{ }^{3} \mathrm{H}-\mathrm{NE}$ responses eliminates decreased neuronal reuptake as the mechanism of high plasma NE levels in clozapine-treated patients.

A buildup of NE in the axoplasm, such as by inhibition of MAO and of the vesicular monoamine transporter, could increase NE release by a nonexocytotic process, via exit through the membrane transporter (Eisenhofer et al. 1986; Hovevey-Sion et al. 1990). The present finding of normal plasma levels of DHPG, ${ }^{3} \mathrm{H}-$ DHPG, and DOPAC in clozapine-treated subjects renders MAO inhibition a highly unlikely mechanism of action of clozapine. Moreover, blockade of the vesicular monoamine transporter accelerates the rate of attain-
Clozapine

Fluphenazine

Placebo
Figure 2. $\left[{ }^{3} \mathrm{H}\right] \mathrm{DHPG} /\left[{ }^{3} \mathrm{H}\right]-\mathrm{NE}$ ratio in schizophrenic patients treated with clozapine $(n=10)$, fluphenazine $(n=7)$, and placebo $(n=7)$. 
ment of plateau ${ }^{3} \mathrm{H}$-DHPG concentrations during ${ }^{3} \mathrm{H}-$ NE infusion (Eisenhofer et al. 1991), and in the present study, clozapine treatment did not alter the slowly progressive increase in plasma ${ }^{3} \mathrm{H}$-DHPG levels.

Clozapine produces blockade of $\alpha 1$ and $\alpha 2$ adrenoceptors (Arbilla et al. 1978; Souto et al. 1979; Richelson and Nelson 1984; Baldessarini and Frankenburg 1991). These actions could increase sympathoneural outflows reflexively in response to systemic vasodilation and also augment NE release for a given amount of nerve traffic, by blocking inhibitory modulatory $\alpha 2$-adrenoceptors on sympathetic nerves (Breier et al. 1994b; Breier 1994). This synergy could then markedly increase exocytotic release of NE. This mechanism alone would not explain the clear finding of normal plasma DHPG levels in clozapine-treated subjects, replicating previous results (Breier et al. 1994b). Because plasma DHPG levels generally parallel plasma NE levels during sympathetic stimulation, by increased reuptake of the released NE (Goldstein et al. 1988; Goldstein 1995), adrenoceptor blockade alone would not account for the pattern of a large increase in plasma NE levels with no change in plasma DHPG levels. Because of the lack of DHPG changes, clozapine would not also be expected to increase NE spillover by only a central mechanism that would increase sympathoneural outflows.

A chronic, substantial increase in the rate of sympathetic nerve traffic might lead to a situation where the rate of exit of NE from the innervated tissues would exceed the rate of synthesis of NE. This would deplete the NE stores and, thereby, decrease production of DHPG. Decreasing the size of the storage pool of NE increases the rate of rise in the specific activity of ${ }^{3} \mathrm{H}-\mathrm{DHPG}$ during ${ }^{3} \mathrm{H}-\mathrm{NE}$ infusion (Eisenhofer et al. 1991; Eisenhofer et al. 1996). In the present study, however, clozapine treatment did not affect the rate of increase in arterial plasma ${ }^{3} \mathrm{H}-\mathrm{DHPG}$ concentrations. A decreased storage pool of NE, therefore, does not explain the discrepancy between plasma NE and DHPG responses to clozapine.

If a chronic increase in the rate of sympathetic nerve traffic increased the relative proportion of vesicles fused with the membrane surface, then we might expect a relative increase in DHPG formation from reuptake of released NE and a relative decrease in DHPG formation from net leakage from the vesicles into the axoplasm. Thus, over-all DHPG production might remain unchanged. Patients with disorders presumably associated with chronically compensatory increased sympathetic nerve traffic, such as dihydropteridine reductase deficiency (Goldstein et al. 1995), Menkes disease (Kaler et al. 1993), familial dysautonomia (Axelrod et al. 1996), and partial deficiency of L-aromatic-amino-acid decarboxylase (unpublished observations), do have high plasma NE:DHPG ratios, consistent with a shift in the vesicles toward the membrane surface, where loss of NE via leakage and metabolism would be offset by loss of NE via exocytosis. Therefore, a mechanism of clozapine's action may involve fusion of NE storage vesicles with the axonal membrane.

In conclusion, clozapine elevates arterial plasma NE levels via increases in NE spillover; whereas, NE reuptake, synthesis, or metabolism are not affected by this drug.

\section{ACKNOWLEDGMENTS}

The authors gratefully acknowledge contributions of Christopher Bir, Michael Wood, Lisa Picken, Jerry Rotter, and the nursing staff of 4 East Clinical Care Unit, National Institutes of Health.

\section{REFERENCES}

Ackenheil M (1989): Clozapine-pharmacokinetic investigations and biochemical effects in man. Psychopharmacology (Berl) 99:S32-7

Arbilla S, Briley MS, Dubocovich ML, Langer SZ (1978): Neuroleptic binding and their effects on the spontaneous and potassium-evoked release of ${ }^{3} \mathrm{H}$-dopamine from the striatum and of ${ }^{3} \mathrm{H}$-noradrenaline from the cerebral cortex. Life Sci 23:1775-1780

Axelrod FB, Goldstein DS, Holmes C, Berlin D, Koplin IJ (1996): Pattern of plasma levels of catecholamines in familial dysautonomia. Clin Auton Res 6:205-209

Baldessarini RJ, Frankenburg FR (1991): Clozapine: A novel antipsychotic agent. N Engl J Med 324:746-754

Breier A (1994): Clozapine and noradrenergic function: Support for a novel hypothesis for superior efficacy. J Clin Psychiatr 55:122-125

Breier A, Buchanan RW, Kirkpatrick B, Davis OR, Irish D, Summerfelt A, Carpenter WT (1994a): Effects of clozapine on positive and negative symptoms in outpatients with schizophrenia. Am J Psychiatr 151:20-26

Breier A, Buchanan RW, Waltrip RW, Listwak S, Holmes C, Goldstein DS (1994b): The effect of clozapine on plasma norepinephrine: Relationship to clinical efficacy. Neuropsychopharmacology 10:1-7

Brown AS, Gewirtz G, Harkavy-Friedman J, Cooper T, Brebion G, Amador XF, Malaspina D, Gorman J (1997): Effects of clozapine on plasma catecholamines and relationship treatment response in schizophrenia: A withinsubject comparison with haloperidol. Neuropsychopharmacology 17:317-325

Davidson M, Kahn RS, Stern RG, Hirschowitz J, Apter S, Knott P, Davis KL (1993): Treatment with clozapine and its effect on plasma homovanillic acid and norepinephrine concentrations in schizophrenia. Psychiatr Res 46: 151-163

Eisenhofer G, Goldstein DS, Stull R, Keiser HR, Sunderland T, Murphy DL, Kopin IJ (1986): Simultaneous liquidchromatographic determination of 3,4-dihydroxyphenylglycol, catecholamines, and 3,4-dihydroxyphenylalanine in plasma, and their responses to inhibition of monoamine oxidase. Clin Chem 32:2030-2033 
Eisenhofer G, Esler MD, Meredith IT, Ferrier C, Lambert G, Jennings $G$ (1991): Neuronal reuptake of noradrenaline by sympathetic nerves in humans. Clin Sci (Colch) $80: 257-263$

Eisenhofer G, Friberg P, Rundqvist B, Quyyumi AA, Lambert G, Kaye DM, Kopin IJ, Goldstein DS, Esler MD (1996): Cardiac sympathetic nerve function in congestive heart failure. Circulation 93:1667-1676

Esler M, Jackman G, Bobik A, Kelleher D, Jennings G, Leonard P, Skews H, Korner P (1979): Determination of norepinephrine apparent release rate and clearance in humans. Life Sci 25:1461-1470

Esler M, Jackman G, Leonard P, Skews H, Bobik A, Korner P (1981): Effect of norepinephrine uptake blockers on norepinephrine kinetics. Clin Pharmacol Ther 29:12-20

Esler M, Jennings G, Lambert G, Meredith I, Horne M, Eisenhofer G (1990): Overflow of catecholamine neurotransmitters to the circulation: Source, fate, and functions. Physiol Rev 70:963-985

Goldstein DS (1995): Stress, Catecolamines, and Cardiovascular Disease. Oxford, UK, Oxford University Press

Goldstein DS, Eisenhofer G, Stull R, Folio CJ, Keiser HR, Kopin IJ (1988): Plasma dihydroxyphenylglycol and the intraneuronal disposition of norepinephrine in humans. J Clin Invest 81:213-220

Goldstein DS, Hahn SH, Holmes C, Tifft C, Harvey-White J, Milstien S, Kaufman S (1995): Monoaminergic effects of folinic acid, L-DOPA, and 5-hydroxytryptophan in dihydropteridine reductase deficiency. J Neurochem 64: 2810-2813

Green AI, Alam MY, Sobieraj JT, Pappalardo KM, Waternaux C, Salzman C, Schatzberg AF, Schildkraut JJ (1993): Clozapine response and plasma catecholamines and their metabolites. Psychiatr Res 46:139-149

Hovevey-Sion D, Eisenhofer G, Kopin IJ, Kirk KL, Chang PC, Szemeredi K, Goldstein DS (1990): Metabolic fate of injected radiolabelled dopamine and 2-fluorodopamine in rats. Neuropharmacology 29:881-887

Iversen LL (1973): Catecholamine uptake processes. Br Med Bull 29:130-135

Kaler SG, Goldstein DS, Holmes C, Salerno JA, Gahl WA (1993): Plasma and cerebrospinal fluid neurochemical pattern in Menkes disease. Ann Neurol 33:171-175

Kane J, Honigfeld G, Singer J, Meltzer H (1988): Clozapine for the treatment-resistant schizophrenic. A doubleblind comparison with chlorpromazine. Arch Gen Psychiatr 45:789-796

Leiberman J, Johns C, Cooper T, Pollack S, Kane J (1989): Clozapine pharmacology and tardive dyskinesia. Psychopharmacology (Berl) 99:S54-59

Leiberman J, Johns C, Pollack S, Masiar S, Bookstein P, Cooper T, Iadorola M, Kane J (1991): Biochemical effects of clozapine in cerebrospinal fluid of patients with schizophrenia: Advances in neuropsychiatry and psychopharmacology. Schizophrenia Res 1:341-349

Meltzer HY (1995): Clozapine: Is another view valid? Am J Psychiatr 152:821-825

Meltzer HY, Thompson PA, Lee MA, Ranjan R (1996): Neuropsychologic deficits in schizophrenia: Relation to social function and effect of antipsychotic drug treatment. Neuropsychopharmacology 14:27S-33S

Pickar D, Owen RR, Litman RE, Konicki E, Gutierrez R, Rapaport MH (1992): Clinical and biologic response to clozapine in patients with schizophrenia. Cross-over comparison with fluphenazine. Arch Gen Psychiatr 49:345-353

Richelson E, Nelson A (1984): Antagonism by neuroleptics of neurotransmitter receptors of normal human brain in vitro. Eur J Pharmacol 103:197-204

Souto M, Monti JM, Altier H (1979): Effects of clozapine on the activity of central dopaminergic and noradrenergic neurons. Pharmacol Biochem Behav 10:5-9 